\title{
XRD Synchrotron Study of Carbide Precipitation in Martensitic Steels During Tempering
}

\author{
C. Bellot ${ }^{1,2)}$, P. Lamesle ${ }^{1)}$ and D. Delagnes ${ }^{1) \dagger}$
}

1) Université de Toulouse; Mines Albi, INSA, UPS, ISAE; ICA (Institut Clément Ader); Campus Jarlard, F-81013 Albi, France

2) Aubert\&Duval, BP1 F-63770 Les Ancizes, France

[Manuscript received 5 February 2013, in revised form 2 June 2013]

(c) The Chinese Society for Metals and Springer-Verlag Berlin Heidelberg

In order to improve the knowledge of the precipitation mechanism in martensitic steels containing carbon, XRD synchrotron experiments were performed. Firstly, the influence of $\mathrm{Ni}, \mathrm{Co}$ and $\mathrm{Al}$ were studied and it was found that the precipitation of iron carbides occurs in same way as in Fe- $\mathrm{C}$ steel. However, with the addition of molybdenum and chromium in same steels, XRD synchrotron investigations clearly showed alloyed carbides directly precipitate, thereby preventing the iron carbides formation.

KEY WORDS: Carbon; Martensite; Iron carbide; Cementite; Precipitation mechanism

\section{Introduction}

In order to produce carbon martensitic steels which are hard and tough, a two-step heat treatment consisting of quenching and tempering is needed. During quenching from its solution annealing temperature, displacive martensitic transformation occurs. The result is a supersaturated solid solution of interstitial carbon atoms in a distorted iron lattice. Depending on the steel's makeup, in terms of carbon and other alloying elements, value of $M_{\mathrm{s}}$ (temperature at the beginning of the martensitic transformation) and the quenching rate, the cementite can precipitate during quenching ${ }^{[1-3]}$. This phenomenon is referred to as auto-tempering. Similarly, the temperature $\mathrm{M}_{\mathrm{f}}$ at which the martensitic transformation is completed to be equal or inferior to the room temperature. Otherwise, a certain volume, referred to as "retained austenite" remains untransformed. Alternatively, a cryogenic treatment can be used to allow the transformation to be complete. After quenching, tempering is needed in order to toughen the material, which would otherwise remain too hard and brittle.

\footnotetext{
† Corresponding author. Ph.D.; Tel.: +33 563493105; Fax: +33 563493341; E-mail address: Cedric.bellot@acrdm.fr (C. Bellot)
}

DOI: $10.1007 / \mathrm{s} 40195-013-0078-\mathrm{z}$
During this step, which can be accomplished either isochronally or isothermally, several decompositions occur, with a certain degree of overlapping or time regions. These reactions have been intensively studied in the past ${ }^{[4-10]}$. In particular, Speich et al. ${ }^{[4]}$ studied martensitic steel with different carbon contents and at different tempering temperatures. At $150{ }^{\circ} \mathrm{C}$ and a carbon content lower to 0.2 wt.\%, Speich showed that the carbon does not precipitate, but segregates at dislocations. For all values of the carbon content, and a temperature greater than $150{ }^{\circ} \mathrm{C}$, the carbon always precipitates in the form of iron carbides.

In summary, the tempering of the carbon martensitic steel can be classified into the following five stages: (1) Stage $1 \quad\left(T<100{ }^{\circ} \mathrm{C}\right)$ : migration of the carbon atoms to dislocations; (2) Stage 2 $\left(100{ }^{\circ} \mathrm{C}<T<200{ }^{\circ} \mathrm{C}\right)$ : precipitation of hexagonal $\varepsilon$ carbides; (3) Stage $3\left(200{ }^{\circ} \mathrm{C}<T<300{ }^{\circ} \mathrm{C}\right)$ : decomposition of the retained austenite into the ferrite and cementite; (4) Stage $4\left(200{ }^{\circ} \mathrm{C}<T<350{ }^{\circ} \mathrm{C}\right)$ : precipitation of the orthorhombic cementite $\mathrm{Fe}_{3} \mathrm{C}$, to the detriment of $\varepsilon$ carbides. Following this step, the matrix is depleted in carbon and losses its tetragonal structure, which is transformed into a cubic ferritic structure; (5) Stage $5\left(400{ }^{\circ} \mathrm{C}<T<600{ }^{\circ} \mathrm{C}\right)$ : if the steel does not contain carbide-forming elements, such as $\mathrm{Cr}, \mathrm{Mo}, \mathrm{V}$ or $\mathrm{W}$, the matrix recovers with a cementite coales- 
Table 1 Compositions (wt.\%) of the studied steels

\begin{tabular}{cccccccc}
\hline Material & $\mathrm{C}$ & $\mathrm{Cr}$ & $\mathrm{Mo}$ & $\mathrm{Ni}$ & $\mathrm{Co}$ & $\mathrm{Al}$ & $\mathrm{Fe}$ \\
\hline C simplified & 0.195 & - & - & 10.53 & - & - & Bal. \\
CCoAl simplified & 0.223 & - & - & 14.35 & 10.00 & 0.85 & Bal. \\
C & 0.213 & 2.39 & 1.40 & 10.49 & - & - & Bal. \\
CCoAl & 0.233 & 2.41 & 1.48 & 14.05 & 9.99 & 0.89 & Bal. \\
Al & 2.38 & - & 11.73 & - & 1.05 & - & Bal. \\
\hline
\end{tabular}

cence and martensitic lath coarsening with recrystallization. If the steel contains carbide-forming elements, cementite dissolution occurs and the alloyed carbides precipitate. After a certain time, and under suitable temperature conditions, these alloyed carbides coalesce.

The steel's behavior during these different stages depends of the heating rate and/or the steel's chemical composition. In addition, certain variations are detected in the temperature associated with each of these stages. However, until now this mechanism has been observed and evaluated only in carboncontaining martensitic steels ${ }^{[9-14]}$. Furthermore, following the industrial heat treatment of the steels with carbide-forming elements, the cementite is not completely dissolved. The presence of these particles, which are relatively coarse and have a heterogeneous distribution, limits the toughness of many martensitic steels $^{[15,16]}$

The main goal of the present study was to use XRD Synchrotron analyses to investigate the influence of various chemical elements on the carbide precipitation mechanism in martensitic steels. Measurements are made at the European synchrotron radiation facility (ASRF, Grenoble, France) with the ID15 line which is dedicated to the high energy diffraction. The interest of this technique is the exploitation to high intensity and penetration depth of the synchrotron radiation for small or weakly present phase detection.

In the continuation of Speich's study ${ }^{[4]}$ of Fe-C martensitic steels with no carbide-forming elements, various experiments were carried out, firstly to determine the influence of a high nickel content on the precipitation mechanisms of iron carbides. In a second step, the combined influence of nickel, cobalt and aluminum on this mechanism was also tested.

Finally, these same parent steels, to which chromium and molybdenum have been added, were also studied. Although these two elements allow alloyed carbides to be precipitated during tempering, they also allow such alloyed carbides to be precipitated directly, thereby shunting the precipitation of iron carbides. This type of the martensitic steel, containing $\mathrm{Ni}$, Co, $\mathrm{Al}$ with $(\mathrm{Cr}, \mathrm{Mo})_{2} \mathrm{C}$, first appeared approximately 15 years ago in the United States. They are characterized by a $\mathrm{Rm} / \mathrm{K} 1 \mathrm{C}$ compromise, which differs from the conventional compromise observed in other carbide-hardened martensitic steels. The diverse precipitation mechanisms observed on the al- loyed carbides could provide one explanation for the latter difference.

\section{Experimental}

Table 1 lists the studied steels, which can be broken into three distinct families. The first, "Simplified steel", is composed of two steels with no carbideforming elements. The so-called "C simplified" steel grade contains iron, carbon and nickel, whereas the "CCoAl simplified" grade also contains cobalt and aluminum. The second, "Alloyed steel" family, is directly inspired from the first family, however these two grades $(\mathrm{C}$ and $\mathrm{CCoAl}$ ) also contain chromium and molybdenum, which are carbide-forming elements. Whereas these two elements allow alloyed $(\mathrm{Cr}, \mathrm{Mo})_{2} \mathrm{C}$ carbides to be precipitated during tempering ${ }^{[17,18]}$, the study of these grades of the steel allows the influence of $\mathrm{Cr}$ and $\mathrm{Mo}$ on iron carbide precipitation to be observed during the first stages of tempering. Finally, the last line in Table 1 corresponds to a reference, carbonless grade of the steel, with a composition very close to that of maraging steels, which have been widely studied in the past. The use of this grade of the steel makes it possible to analyze the behavior of a matrix without carbon.

All of these grades of the steel were subjected to the same heat treatment, with a solution annealing at $900{ }^{\circ} \mathrm{C}$ for one hour, air quenching, cryogenic treatment at $-80{ }^{\circ} \mathrm{C}$, initial tempering for $8 \mathrm{~h}$ at $200{ }^{\circ} \mathrm{C}$, and a second tempering operation at $500{ }^{\circ} \mathrm{C}$. Cryogenic treatment allows austenite to be completely transformed into martensite.

Several samples were studied after tempering at $500{ }^{\circ} \mathrm{C}$, by means of post-mortem synchrotron XRD. Compared to the traditional characterization techniques, the synchrotron XRD technique can provide much information, since the time required for collecting data is greatly reduced by employing a 2 dimensional (2D) large area detector in transmission mode (Fig. 1). The photon energy used for these measurements was $87 \mathrm{keV}$, corresponding to a wavelength of $0.01414 \mathrm{~nm}$. The exposure time was $20 \mathrm{~s}$ per scan. The obtained 2D diffraction patterns were calibrated by using a reference material and converted to $1 \mathrm{D}$ patterns by using Fit2D software.

\section{Results and Discussion}

For the reference steel, only the BCC-B2 intermetallic phases were detected by XRD synchrotron 


\section{D-detector}

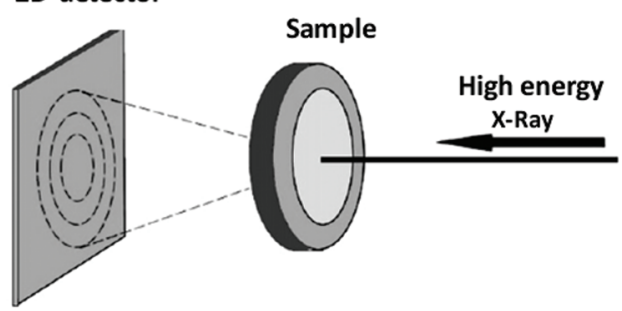

Fig. 1 Schematic diagram of high energy synchrotron XRD experiment

analysis, after tempering $4 \mathrm{~h}$ at $500{ }^{\circ} \mathrm{C}$, which is in agreement with results obtained using other experimental techniques ${ }^{[17,18]}$.

\subsection{Simplified steels}

In Fig. 2, diffraction spectra of simplified steels are shown during tempering at $500{ }^{\circ} \mathrm{C}$, for the periods varying between $20 \mathrm{~min}$ and $100 \mathrm{~h}$.

In the aluminum-containing $\mathrm{CCoAl}$ steel, the bcc$\mathrm{B} 2$ intermetallics are indexed after $4 \mathrm{~h}$ of tempering at $500{ }^{\circ} \mathrm{C}$ which is in good agreement with the observations made with the reference steel and with the same grades of steel using other experimental techniques $^{[17,18]}$, and with the results obtained in different maraging steels containing aluminum ${ }^{[19,20]}$.

For both steels, cementite $\left(\mathrm{Fe}_{3} \mathrm{C}\right)$ is clearly indexed after $20 \mathrm{~min}$ at $500{ }^{\circ} \mathrm{C}$. The refinement of the cementite peaks observed between $20 \mathrm{~min}$ and $20 \mathrm{~h}$ confirm that these particles were coalescing. With the CCoAlsimplified grade of the steel, no cementite or iron carbides were still existing after $100 \mathrm{~h}$. This is the first time that such an outcome has been reported. In maraging steels with a high nickel content, reversion austenite forms during the tempering ${ }^{[21]}$. In this steel, after tempering for a long time, the carbon stabilizes the reversion austenite, and which is more stable in this phase than the iron carbides.

In agreement with previous studies, in these steels, the carbon forms iron carbides at the beginning of the tempering process, and the addition, firstly of nickel, then of cobalt and aluminum, does not modify the classical precipitation mechanism.

\subsection{Alloyed steels}

The diffraction patterns obtained with alloyed steels are shown in Fig. 3. Samples B300 and B400 correspond to heating at 300 and $400{ }^{\circ} \mathrm{C}$, respectively, directly followed by quenching.

In the $\mathrm{C}$ alloyed steel, cementite is clearly indexed at the beginning of the tempering process, as in the case of the Csimplified steel. However, the cementite diffraction peaks are much less intense in the case of the alloyed steel, meaning that the fraction of the cementite is considerably lower in the $\mathrm{C}$ alloyed grade than in the Csimplified steel. The $(\mathrm{Cr}, \mathrm{Mo})_{2} \mathrm{C}$ carbides are precipitated after a period ranging between 10 and $100 \mathrm{~h}$ of tempering. This result is in agreement with the results reported for this grade of steel, using different measurement techniques ${ }^{[17,18]}$.

For the CCoAl alloyed steel, although no cementite were indexed in the B300 and B400 samples, $\varepsilon$ carbides were precipitated with very low peak intensities, meaning that the fraction of the iron carbides was also much lower in the alloyed version than in the simplified steel. In agreement with other studies, $\mathrm{Al}$ stabilizes $\varepsilon$ to the detriment of the cementite, due to a reduced misfit between these carbides and the matrix ${ }^{[22]}$. The $(\mathrm{Cr}, \mathrm{Mo})_{2} \mathrm{C}$ carbides are clearly indexed after $10 \mathrm{~h}$ at $500{ }^{\circ} \mathrm{C}$, and the kinetics precipitation are faster with the addition of cobalt. This phenomenon has already been observed by other authors, in carbon martensitic steels ${ }^{[15,23,24]}$. In the present study, it was found that after $20 \mathrm{~min}$ at $500{ }^{\circ} \mathrm{C}$, only the bcc-A2 structure was present in the diffraction spectra, with no iron or alloyed carbides being precipitated. This means that carbon is not precipitated, but remains in solution in the matrix.

\subsection{Matrix}

In order to confirm that carbon is not precipi-

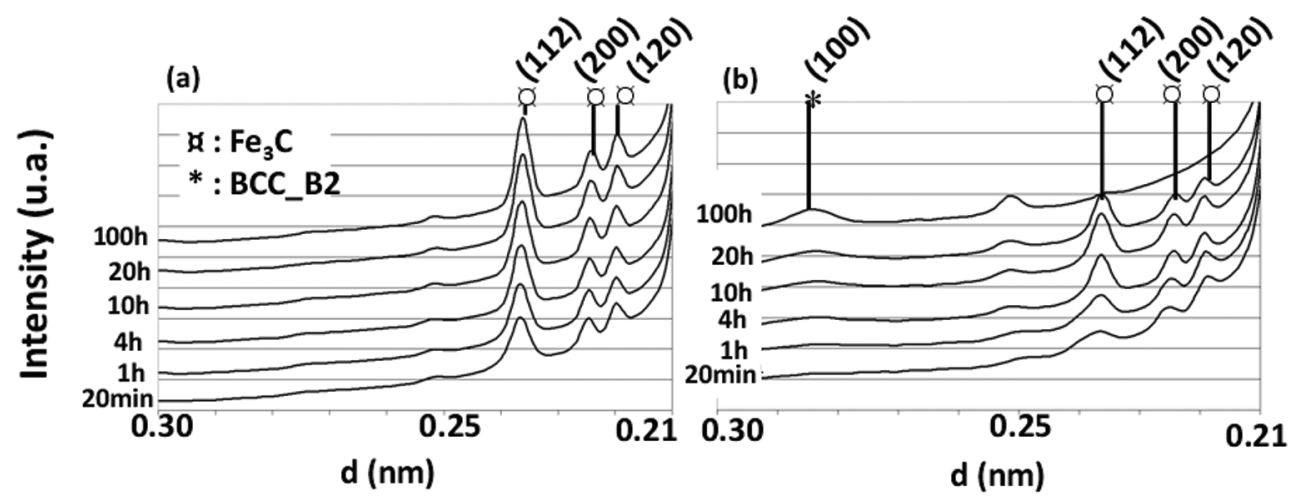

Fig. 2 Synchrotron XRD spectra for the C simplified (a) and CCoAl simplified (b) grades after tempering at $500{ }^{\circ} \mathrm{C}$ for different time 

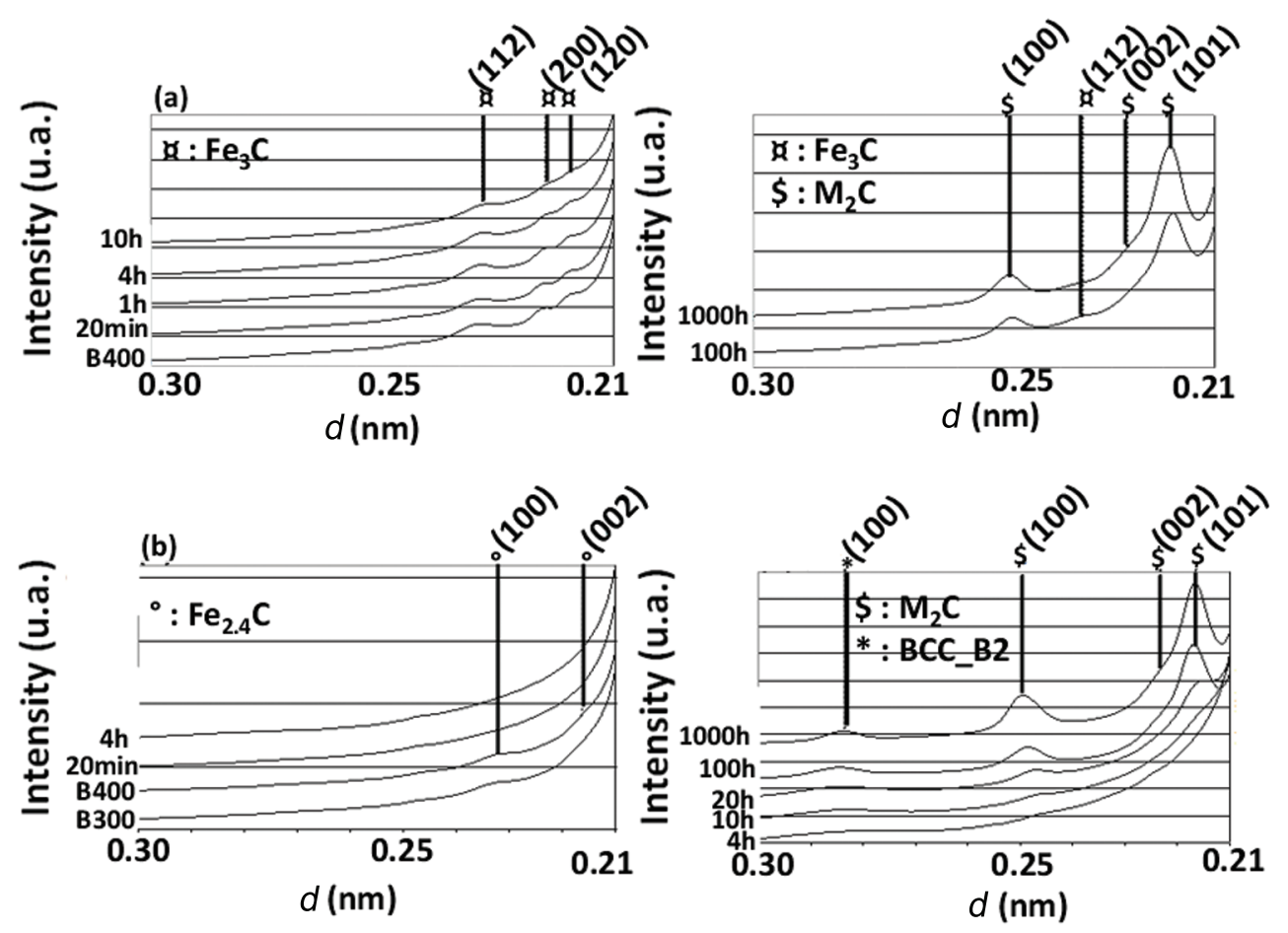

Fig. 3 Synchrotron XRD spectra for the C (a) and CCoAl (b) alloyed grade for simple temperature ramps up to 300 and $400{ }^{\circ} \mathrm{C}$, respectively, directly followed by cooling down to room temperature, and tempering at $500{ }^{\circ} \mathrm{C}$ for various time

tated in alloyed steel contrary to the case of simplified steel, FWMH of the (200) matrix diffraction peak were determined, and then used to compare the different studied families.

In the case of the carbonless reference steel, the FWMHs were very small in value, and remained constant during tempering (Fig. 4). In simplified steel, the cementite precipitates at the beginning of tempering, leading to total carbon depletion of the matrix. Thus, in good agreement with this observation, the FWMH values for simplified steel are found to be close to those of the carbonless reference steel.

In the case of the alloyed steel, the variations in diffraction peak FWMHs during tempering were very different from those of the reference and simplified steels. Indeed, at the beginning of the tempering process, the FWMHs were very broad. During tempering, the FWMHs decrease and approach the values calculated for other steels, after $1000 \mathrm{~h}$ at $500{ }^{\circ} \mathrm{C}$. Kurdjumov et al. ${ }^{[25]}$ proposed a relationship relating the diffraction peaks of martensitic steels to the carbon content of the matrix. In the case of high carbon content, two distinct matrix peaks (a doublet) can be clearly indexed, due to the high $c / a$ ratio of the distorted martensitic matrix. However, although the FWMH is very broad due to the presence of these two peaks, when the steel has a very low carbon content only one peak can be identified, because the $c / a$ ratio is very close to 1 . When the carbon content of the matrix

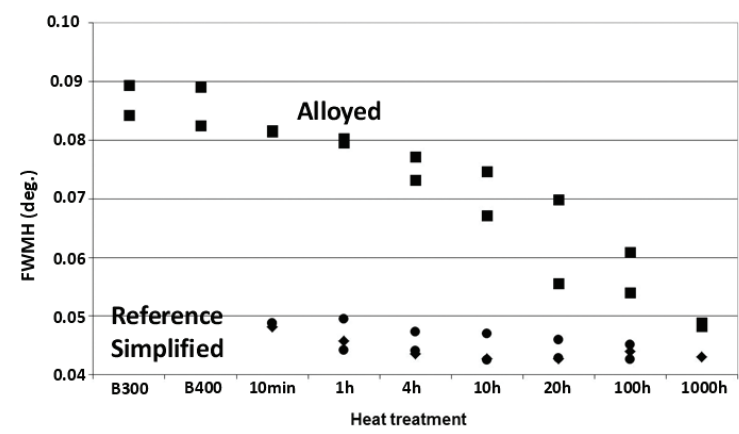

Fig. 4 FWMH variations during tempering for the studied steels

decreases, these two peaks come closer together, resulting in an experimentally observed decrease in FWMH. The variation in diffraction peak FWMH observed in alloyed steel, coupled with the peak intensities measured in iron carbides (presented in the previous section), thus confirm that the precipitation mechanism in alloyed steels is very different from that observed in simplified steels. Although a very low carbon content can precipitate in the form of iron carbides at the beginning of tempering, most of this content remains in the matrix and directly enriches carbon clusters (initially), followed by carbon, chromium and molybdenum clusters. After tempering for a very long time, and depending on the presence of other chemical elements such as Co, these 
clusters acquire their hexagonal $M_{2} \mathrm{C}$ crystallographic structures, shunting the precipitation of iron carbides contrary that it has been widely described in the literatures ${ }^{[1-8]}$.

\section{Conclusions}

In simplified steel, in the absence of carbideforming elements, cementite precipitates at the beginning of tempering and the presence of $\mathrm{Co}, \mathrm{Ni}$ and $\mathrm{Al}$ do not modify this precipitation process. In the presence of $\mathrm{Ni}$ and reversion austenite, after tempering for a long time, carbon stabilizes the reversion austenite, to the detriment of iron carbides.

In alloyed steel containing carbide-forming elements ( $\mathrm{Cr}$ and $\mathrm{Mo}$ ), very small quantities of iron carbide can precipitate at the beginning of tempering. However, most of the carbon content does not precipitate, and remains in the matrix. As tempering progresses, initially only carbon is segregated. Then, after tempering for a long time, and in the presence of chromium and molybdenum, $M_{2} \mathrm{C}$ carbides form. The precipitation of alloyed carbides in martensitic steel is possible without iron carbide precipitation.

This result is very significant, because iron carbides have a highly deleterious influence on a steel's toughness, and are responsible for the non-uniform distribution of alloyed carbides precipitated in the matrix. The direct precipitation of alloyed carbides during tempering is a new avenue of the research, for the development of steels with improved mechanical properties.

\section{REFERENCES}

[1] G. Murry, Transformations dans les aciers, Techniques de l'ingénieur M1115 (1998).

[2] J.E. Krzanowski, Mater. Res. Soc. Symp. Proc. 62 (1986) 273.

[3] H.K.D.H. Bhadeshia, Bainite in Steels, 2nd ed., Cambridge Institute of Materials, 2001, p.124.
[4] G.R. Speich and W.C. Leslie, Metall. Trans. 3 (1972) 1043.

[5] G.B. Olson and M. Cohen, Metall. Mater. Trans. A 14 (1983) 1057.

[6] M.K. Miller, P.A. Beaven and G.D.W. Smith, Metall. Mater. Trans. A 12 (1981) 1197.

[7] K.A. Taylor, G.B. Olson, M. Cohen and J.B. Van der Sande, Metall. Trans. A 20 (1989) 2749.

[8] L. Cheng, C.M. Brakman, B.M. Korevaar and E.J. Mittemeijer, Metall. Mater. Trans. A 19 (1988) 2415.

[9] G. Ghosh and G.B. Olson, Acta Mater. 50 (2002) 2099.

[10] P. Jacques, E. Girault, T. Catlin, N. Geerlofs, T. Kop, S. Van der Zwaag and F. Delannay, Mater. Sci. Technol. A 273-275 (1999) 475.

[11] W.S. Owen, Trans. Amer. Soc. Met. 46 (1954) 812.

[12] J.H. Jang, I.J. Kim and H.K.D.H. Bhadeshia, Scr. Mater. 63 (2010) 121.

[13] E. Kozeschnik and H.K.D.H. Bhadeshia, Mater. Sci. Technol. 24 (2008) 343.

[14] C.K. Ande and M.H.F Sluiter, Acta Mater. 55 (2010) 6276.

[15] G.R. Speich, Metall. Trans. 4 (1973) 1043.

[16] W.M. Garrison and M.A. Rhoads, Trans. Indian Inst. Met. 49 (1996) 151.

[17] D. Delagnes, F. Pettinari-Sturmel, M.H. Mathon, R. Danoix, F. Danoix, C. Bellot, P. Lamesle and A. Grellier, Acta Mater. 60 (2012) 5877.

[18] F. Danoix, R. Danoix, J. Akre, A. Grellier and D. Delagnes, J. Microscopy 244 (2011) 305.

[19] S.D. Erlach, H. Leitner, M. Bischof, H. Clemens, F. Danoix, D. Lemarchand and I. Siller, Mater. Sci. Eng. A 429 (2006) 96.

[20] D.H. Ping, M. Ohnuma, M. Hirakawa, Y. Kadoya and K. Hono, Mater. Sci. Eng. A 394 (2005) 285.

[21] U.K. Viswanathan, G.K. Dey and V. Sethumadhavan, Mater. Sci. Eng. A 398 (2005) 367.

[22] W.C. Leslie and G.C. Rauch, Metall. Trans. A 9 (1978) 343

[23] K.B. Lee, H.R. Yang and H. Know, Metall. Mater. Trans. A 32 (2001) 1659.

[24] H. Know, K.B. Lee and H.R. Yang, Metall. Mater. Trans. A 27 (1996)

[25] G.V. Kurdjumov and A.G. Khachaturyan, Acta Metall. 23 (1975) 1077. 